\title{
Commentary \\ The Inauguration of a New Term of Pediatric Endocrinology
}

\author{
Scott A. Rivkees \\ Yale Child Health Research Center, Yale University School of Medicine, 464 Congress Avenue, Room 237, \\ New Haven, CT 06520, USA \\ Correspondence should be addressed to Scott A. Rivkees, scott.rivkees@yale.edu
}

Received 30 January 2009; Accepted 3 February 2009

Copyright (c) 2009 Scott A. Rivkees. This is an open access article distributed under the Creative Commons Attribution License, which permits unrestricted use, distribution, and reproduction in any medium, provided the original work is properly cited.

"We will restore science to its rightful place, and wield technology's wonders
to raise health care's quality and lower its cost."
President Barack Obama's Inaugural Address
January 20th, 2009

The joy of the recent inauguration of Barack Obama as President of The United States has given a bounce to medicine and scientific communities, with the no-growth science policies of the past administration ushered out, replaced by promises of enhanced support for science and health care reform [1]. The past eight years of the Bush administration have seen National Institutes of Health (NIH) funding increase by about $20 \%$ for the first four years, followed by decreases over the later four years [2]. The recent stagflation of science spending has resulted in significant hardship for biomedical research.

Whereas NIH research funding has remained flat of late, the upward trend of health care spending continues. It is now estimated that US health care spending is more than $17 \%$ of the Gross Domestic Product (GDP), the highest percentage in the world [3]. This spending occurs at a time when 46 million Americans, or $15 \%$ of the population, do not have health insurance [3]. Recognizing major problems of the current health care system, federal spending on health care will increase by the hundreds of billions of dollars. However, investment in research and health care will be tempered by the horrible national budget deficit and the poor economy. Thus, health care will "need to do more with less."

The consequences of the United States and global financial crises are real and impact all of us in medicine, either these effects be direct or indirect. Direct consequences of the crisis are funded projects stopped midstream, when the coffers of foundations supporting research had their valuations of $40 \%$ or more, or were swindled [4]. Direct consequences of reduced federal support of research are marked drops in pay lines by NIH institutes to single digits. Direct consequences of the current situation are falling revenues of pharmaceutical companies, leading to reduced industry-sponsored research. Direct consequences come from reduced philanthropic support of medical research and social programs by universal belt-tightening.

Indirect consequences of the current fiscal meltdown come from the parents of our patients in our care who have lost their jobs and no longer have health insurance, leading to reduced hospital revenues. Indirect consequences come when spouses of medical workers loose their jobs and the families relocate taking away valuable medical team members. Indirect consequences related to new hardships of recruiting, which already very difficult in academic pediatrics, are challenged by the inability to sell one's home or to obtain mortgage financing in the new community.

Academic medicine has gone through a painful period over the past decade. Talks of "where were all the young ones gone," lamenting the dwindling pipeline of young research talent, dominated the early part of the current decade. Such commentaries have now expanded to lament the fall of academic departments and entire disciplines $[5,6]$. In pediatrics, research funding has dropped by substantial amounts over the past decade [5-7].

Much of the leadership in pediatrics and pediatric endocrinology, by virtue of being born in the $40 \mathrm{~s}, 50 \mathrm{~s}$, or $60 \mathrm{~s}$, knows the landscape of the past years of healthy funding and reimbursement rates; but, the academic and 
clinical care plains are different now, and will continue to evolve, affected by market and federal events with permanent impact. Whether we like it or not, new times are here.

The core commitment to basic academic principles- the significant scientific advancement of our field, the training of the next generation of clinicians and scholars, and ensuring the health of the boys and girls in our care-will remain as basic tenets. What we need to consider is how will we meet these obligations with less resources. How and where should the old-world of academic endocrinology changed?

One can legitimately ask, for example, can we still afford to fund fellows for three years, as mandated by the American Board of Pediatrics, when fellows desire clinician or clinician educator positions. There are about 50 firstyear fellows in Pediatric Endocrinology in the United States. A third year of fellowship for three quarters of this group costs collective $\$ 2.5$ million annually, and contributes to our current subspecailist shortage.

We need to revisit the current expensive model of physician-only care. As with many centers where diabetes care is delivered largely by nurses or nurse practitioners, such models will need to be expanded for general pediatric endocrinology care.

We need to evaluate the cost-effectiveness of basic practice approaches. Is there benefit to see a child on growth hormone therapy three or four months, as many in the field do, versus every six months? Why do we commit some patients to long-term antithyroid drug therapy for Graves' disease, along with associated risks and extra costs, when we can predict at the onset that chances of remission off antithyroid medicine are slim? Why do we universally perform expensive stimulation testing for growth hormone deficiency at the behest of insurance companies, when we have little faith in such studies?

We need to revisit the corporate influences that drive the cost of our practice. The Veterans Hospitals Administration and several health maintenance organizations, control costs by limiting the drugs that can be prescribed, shunning higher price new drugs in favor of generic compounds with proven efficacy and safety. We need to ask ourselves what are the true advantages of the classic growth hormone products over the lower-priced biosimilar growth hormone. We need to ask ourselves, what are the true advantages of new and more expensive preparations of drugs used to stop puberty over products that are available for more than a decade. Why do we not prescribe generic levo-thyroxine for all hypothyroid patients on such therapy?

We need to ask ourselves do we all need to offer specialty endocrine surgery programs such as for hyperinsulinism or thyroid disorders, when data clearly show that children are best cared for at high volume and specialty centers of excellence. Some insurance companies will give patients a bonus if they go to specialty centers, with the hope that minimizing complication risks will save dollar in the future.

Washington is now abuzz with talk of health care reform, which will take a long and laborious trail. It is clear that new economic models for health care delivery are needed to provide health care to all and to avail us the rich benefit of improving clinical care through biomedical research.
The time for head-wagging and fist-pumping in lament of the past ways of the academic center and biomedical research has past. It is clear that we are all going to have to do more with less. Commensurate the new hope of action that has arrived in Washington, it is now our turn to work for a "new deal" that will reshape our profession into a realistic model for the lasting and chilly times ahead for academic medicine and health care.

\section{References}

[1] B. Obama, "President Barack Obama's Inaugural Address," http://www.whitehouse.gov/blog/inaugural-address.

[2] "Summary of NIH Research Funding Trends, FY1995-2009," 2009, http://www.faseb.org.

[3] The National Coalition on Health Care, "Facts on the Cost of Health Insurance and Health Care," 2009.

[4] N. D. Kristof, "Madoff and America's (poorer) Foundations," The New York Times, January 2009.

[5] S. A. Rivkees and M. Genel, "American pediatric academia: the looming question," The Journal of Pediatrics, vol. 151, no. 3, pp. 223-224, 2007.

[6] M. Genel, M. A. McCaffree, K. Hendricks, et al., "A National Agenda for America's Children and Adolescents in 2008: recommendations from the 15th Annual Public Policy Plenary Symposium, annual meeting of the Pediatric Academic Societies, May 3, 2008," Pediatrics, vol. 122, no. 4, pp. 843-849, 2008.

[7] D. P. Gitterman and W. W. Hay Jr., "That sinking feeling, again? The state of national institutes of health pediatric research funding, fiscal year 1992-2010," Pediatric Research, vol. 64, no. 5, pp. 462-469, 2008. 